\title{
Physician intention to counsel on physical activity: results from a pilot theory of planned behavior questionniare
}

Timothy K. Behrens ${ }^{1 *}$ and Vanessa J. Harbour ${ }^{2}$

*Correspondence: tbehrens@uccs.edu

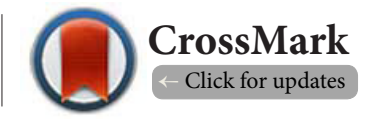

'Department of Health Sciences, University of Colorado, Colorado Springs, USA.

${ }^{2}$ Independent health consultant based in Los Angeles, CA, USA.

\begin{abstract}
Background: Physical activity has been identified as a behavior linked to reducing and preventing chronic disease. Physician counseling may represent an effective way to promote physical activity to a variety of populations. Still, counseling for physical activity is not broadly understood by physicians. Thus, the purpose of this study was to examine primary care provider's intention to counsel patients on engaging in physical activity.

Methods: Using the Theory of Planned Behavior as a guide, a questionnaire was developed to investigate behavioral determinants for counseling patients on physical activity. Participants $(n=26)$ were primary care providers in community clinics. To identify theoretical constructs influencing behavioral intention, two regressions were performed: 1) a multiple regression using direct measures of intention (Theory Model), and 2) a forward selection regression (Best Fit Model).

$\underline{\text { Results: }}$ Subjective norms and perceived behavioral control accounted for the greatest variance in intention in both the Theory Model and Best Fit Model.
\end{abstract}

Conclusions: Additional investigation can identify specific determinants that impact primary care providers' intention to counsel on PA.

Keywords: Communication, exercise, behavior change, physical fitness

\section{Background}

Physical activity has been identified as a behavior linked to reducing and preventing cardiovascular disease, stroke, some cancers, type 2 diabetes, high blood pressure, depression, overweight/obesity, and metabolic syndrome $[1,2]$. Recent vital statistics data indicate chronic diseases- heart disease, stroke, cancer, and type 2 diabetes - among the top 10 causes of death among Americans [3]. According to a press release by the US Government, chronic diseases are attributed to approximately $70 \%$ of all causes of death and approximately $75 \%$ of all medical spending in the nation [4]. Regular, consistent physical activity at the individual level could alleviate much of the burden disease on both the individual level and on the broader, public health level.

Current data reflect roughly $40 \%$ of the population engages in leisure time physical activity, and/or moderate, or vigorous physical activity [5]. Moderate physical activity (MPA) is considered "brisk waking with noticeably accelerated heart rate" [1] requiring an individual to engage in for at least 30 minutes on a minimum of 5 days per week. Vigorous physical activity (VPA) is any vigorously intense physical activity and is defined by "jogging, and causes rapid breathing and substantial increase in heart rate" [1] a minimum of 20 minutes at least 3 days per week, as defined by the American College of Sports Medicine and the American Heart Association [1]. In response to the mounting scientific evidence to support physical activity as prevention and treatment for chronic disease national guidelines were developed, and more recently, revised and updated in Healthy People 2020 [6]. In order to increase the current number of individuals who are engaging in regular physical activity, Healthy People 2020 outlines numerous ways to increase physical activity in the US population and includes an objective to increase counseling on physical activity by a primary care provider [6]. 
This recommendation may be due, in part, to a large majority (82\%) of individuals who reportedly visit a doctor on a yearly basis [7]. Americans average three office visits each year, with $60 \%$ of those visits to their primary care provider $[8,9]$. As a group, primary care providers have contact with a significant number of individuals on a reoccurring basis. Each visit is an opportunity to make an impact on both an individual's health and the health of the American adult population. Patients often do not know what preventive health measures to take, are not aware of lifestyle changes that can positively impact their lives, have poor attitudes toward activity, and can be unmotivated to change. Physicians have an opportunity with each visit to change these perceptions. Patients desire primary care provider advice but infrequently solicit it [8-10]. By initiating discussions, and counseling on physical activity, primary care provider can assess and modify current activity levels, which in turn can change the health outcomes of their patients. It is necessary to understand primary care provider beliefs, perceptions, and motivations towards counseling on physical activity to determine best practices to inform and guide primary care providers on this issue.

Current data regarding physician counseling behavior is not encouraging. When examining physicians as a whole, as much as $60 \%$, are not counseling on physical activity [11]. Widely accepted determinants of physician behavior are the foundation with which interventions are structured [7-10]. Interestingly, those determinants found in historical literature [12] are those same determinants that are being targeted in today's intervention research. Because so much can change over time (e.g., physician demographic, the structure they practice medicine, and disease prevention recommendations), and the unique needs vary over geographic locations, it would seem efficacious to identify specific determinants of primary care providers counseling behavior. That is, what are the barriers (to counseling on physical activity) unique to primary care providers practicing in a specific community? Interventions based on these determinants could potentially lead to increased counseling on physical activity.

In an effort to increase primary care provider counseling patients on engaging in physical activity, researchers have recommended using theory as the framework, pointing toward identifying barriers and facilitators of performing the behavior. Ajzen, Albarracin, and Hornik [13] explained that researchers commonly make the mistake of investigating a relationship between well-known or assumed factors of behavior when no relationship exists. Rather than selecting determinants at random and linking those to a behavior, the theory of planned behavior founders, Fishbein and Ajzen [14], examine behavior to determine beliefs that hinder or facilitate the performance of that particular behavior [13]. The theory of planned behavior was developed to enable researchers to evaluate and predict a behavior by investigating a distinct set of constructs and expanding on those to identify particular beliefs associated with those constructs. Understanding predictors of behavior in primary care providers is critical to developing an appropriate (and successful) intervention to increase physical activity counseling.

The Theory of Planned Behavior has been used in physical activity literature to assess various at-risk populations' (elderly, overweight, and diseased patients) intentions to engage in physical activity or exercise [15-19]. The literature suggests this theory has some success in explaining physician behavior on a variety of health issues concerning their patients [20], however, the theory has not been used to assess primary care provider's behaviors toward counseling patients on physical activity or developing interventions to change primary care provider behavior in counseling patients to engage in physical activity.

The purpose of this study was to examine primary care provider's intention to counsel patients on engaging in physical activity. Using the theory of planned behavior as a guide, elicitation interviews were conducted and a questionnaire was developed to identify primary care providers' behavioral determinants for counseling patients on physical activity. The final questionnaire was administered to primary care physicians to collect information on their intention to counsel patients on engaging in physical activity.

\section{Methods}

Identification of determinants that lead to intention to perform the behavior are essential for intervention development in the area of primary care provider counseling patients on physical activity, and the utility of the theory in this population. Thus, this cross-sectional study applied correlation research methods to examine primary care provider's intention to counsel patients on physical activity. Determinants of behavior were elicited from primary care providers and then included in a questionnaire to evaluate factors that influence intention. Relationships between Theory of Planned Behavior constructs were examined to identify which constructs had a statistically meaningful influence on intention.

Data collection using an intention questionnaire was conducted with primary care providers in community clinics. Participants $(n=26)$ included family medicine physicians and general internists [are a medical doctor (MD) or a doctor of osteopathy (DO)], and resident family medicine physicians (PGY2 \& PGY3), aged 18-65 years old, English speaking, and serving patients in seven university clinics and community clinics.

Participants consented by submitting the questionnaire. Approval from University IRB and from the University health research network was obtained. Access was then granted the study population. Grant funding was awarded through the University's Department of Family and Preventative Medicine.

\section{Measures}

Participants completed a short questionnaire consisting of demographic information to describe the study population 
and the intention to counsel items; the questionnaire developed to assess theoretical constructs of the Theory of Planned Behavior. Determinants of behavior were elicited from primary care providers and then included in a questionnaire to evaluate factors that influence intention to counsel patients on physical activity. Relationships between Theory of Planned Behavior constructs were examined to identify which constructs had a statistically meaningful influence on intention.

\section{Procedures}

Elicitation interviews were conducted and a questionnaire guided by the theory of planned behavior was developed to gather construct specific beliefs that are known to influence intention. The intention survey was designed based on data collected from these interviews. The intention survey was distributed in person during clinic provider meetings and to physicians during regular clinic hours. The health research network coordinated with clinic providers to collect data from family medicine physicians, general internists, and family medicine residents serving the university community clinics. A questionnaire cover letter was included.

\section{Analysis}

Descriptive statistics were collected for primary care providers' characteristics, including physical activity scores on the International Physical Activity Questionnaire. Two Pearson Correlation Coefficient calculations were conducted on theoretical constructs. Relationships between indirect measure items and direct measure items were examined first. Secondly, relationships between the direct measure items were examined.

Multiple regression statistics were conducted to evaluate the significance of each construct to influence intention. The first regression analysis used indirect measures with corresponding direct measures score together as the independent variables and intention as the dependent variable. Composite score was created by multiplying each behavioral belief by the corresponding outcome evaluation, then summing these scores together to create a composite score. This composite score was then summed with the direct measure score for attitude to create a total composite direct measure score. Composite scores for subject norms, and perceived behavioral control were also conducted using the relevant indirect measures summed with the corresponding direct measure as done with the direct and indirect measure for attitude. A multiple regression was performed to predict intention.

The second regression analysis conducted used only the direct measures of intention (attitude, subjective norms, and perceived behavioral control) to predict intention. This was termed the Theory Model. Lastly, a forward regression analysis was conducted to identify a Best-Fit Model; a regression equation that includes only the direct measure (s) that accounted for the most variance in intention and also maintained a level of significance.

\section{Results}

\section{Participant characteristics}

Study participants included 26 primary care providers. The sample was nearly evenly split between males $(42.31 \%)$ and females (57.69\%). Table 1 presents characteristics for participants. The majority of the sample was Caucasian (84.62\%). One half of the sample graduated within the previous 10 years. A single internist participated in the questionnaire; all other participants in phase two were family practitioners.

Table 1. Demographics.

\begin{tabular}{llll}
\hline Variable & $\begin{array}{l}\text { Male } \\
(\mathbf{n = 1 1})\end{array}$ & $\begin{array}{l}\text { Female } \\
(\mathbf{n = 1 5})\end{array}$ & $\begin{array}{l}\text { Total } \\
(\mathbf{N}=\mathbf{2 6})\end{array}$ \\
\hline Age & $\begin{array}{l}43.45 \pm 9.03 \\
(37.39-49.52)\end{array}$ & $\begin{array}{l}34.73 \pm 8.13 \\
(30.23-39.23)\end{array}$ & $\begin{array}{l}38.42 \pm 9.43 \\
(34.61-42.23)\end{array}$ \\
& $11(100.00)$ & $11(73.33)$ & $22(84.62)$ \\
Percent caucasian & & & \\
Year graduated & & $9(60.00)$ & $13(50.00)$ \\
1999- Present & $4(36.36)$ & $5(33.33)$ & $7(26.92)$ \\
1989-1998 & $3(18.19)$ & $1(6.67)$ & $6(23.08)$ \\
Before 1987 & $5(45.45)$ & & \\
Type & & & $24(96.00)$ \\
Family practitioner & $8(90.00)$ & $15(100.00)$ & $1(4.00)$ \\
Internist & $1(10.00)$ & $0(0.00)$ & \\
\hline
\end{tabular}

Note: Percent Caucasian=N(\%); For Type, $\mathrm{N}$ is not equal for this question.

\section{Intention analysis}

Questionnaires were collected and compiled for analysis. Correlations between the theoretical variables and level of significance are presented in Table 2.

A multiple regression analysis was conducted. A forward selection was used to identify a model for best-fit. Figure 1 presents this model. This enabled the researcher to see which predictor variables accounted for a significant level of variance and improve upon the correlation statistic ( $r$ ). This analysis

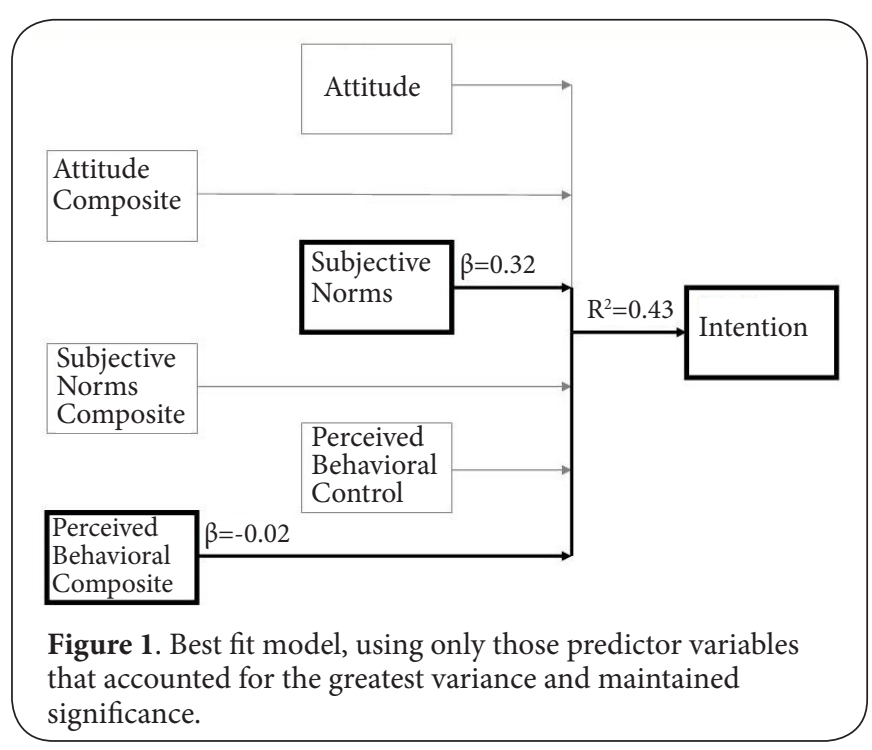


Behrens et al. Journal of Public Health Aspects 2014,

http://www.hoajonline.com/journals/pdf/2055-7205-1-2.pdf

doi: $10.7243 / 2055-7205-1-2$

Table 2. Pearson correlation coefficients.

\begin{tabular}{|c|c|c|c|c|c|c|c|}
\hline & Intention & Attitude & $\begin{array}{l}\text { Subjective } \\
\text { norms }\end{array}$ & $\begin{array}{l}\text { Perceived } \\
\text { behavioral control }\end{array}$ & $\begin{array}{l}\text { Attitude } \\
\text { composite }\end{array}$ & $\begin{array}{l}\text { Subjective norms } \\
\text { composite }\end{array}$ & $\begin{array}{l}\text { Perceived behavioral } \\
\text { control composite }\end{array}$ \\
\hline Intention & 1.00 & - & -- & -- & -- & -- & -- \\
\hline Attitude & $0.44^{*}$ & 1.00 & -- & -- & -- & -- & -- \\
\hline Subjective norms & $0.49^{\dagger}$ & 0.55 & 1.00 & -- & -- & -- & -- \\
\hline $\begin{array}{l}\text { Perceived behavioral } \\
\text { control }\end{array}$ & -0.12 & 0.20 & $0.33^{*}$ & 1.00 & -- & -- & -- \\
\hline Attitude composite & 0.32 & $0.71^{\dagger}$ & $0.64^{\dagger}$ & 0.27 & 1.00 & -- & -- \\
\hline $\begin{array}{l}\text { Subjective norm } \\
\text { composite }\end{array}$ & 0.26 & $0.39^{*}$ & $0.43^{*}$ & 0.26 & $0.52^{\dagger}$ & 1.00 & -- \\
\hline $\begin{array}{l}\text { Perceived behavioral } \\
\text { control composite }\end{array}$ & $-0.41^{*}$ & -0.29 & -0.01 & $0.45^{*}$ & -0.61 & 0.20 & 1.00 \\
\hline
\end{tabular}

Note: ${ }^{\star} \mathrm{p}<0.05, \dagger \mathrm{p}<0.01$.

showed that $43.33 \%$ of the variance in intention scores are accounted for by subjective norms $(p \leq 0.01)$, and the composite score for perceived behavioral control $(p \leq 0.01)$.

Continuing to add variables in the forward regression, theoretical model includes all constructs, resulted in a small increase in the prediction of intention, The Theory Model results indicated $51.00 \%$ of the variance in intention was accounted for (subjective norms $p \leq 0.05$ ), however, there was a loss in significance of the predictor variables Figure 2.

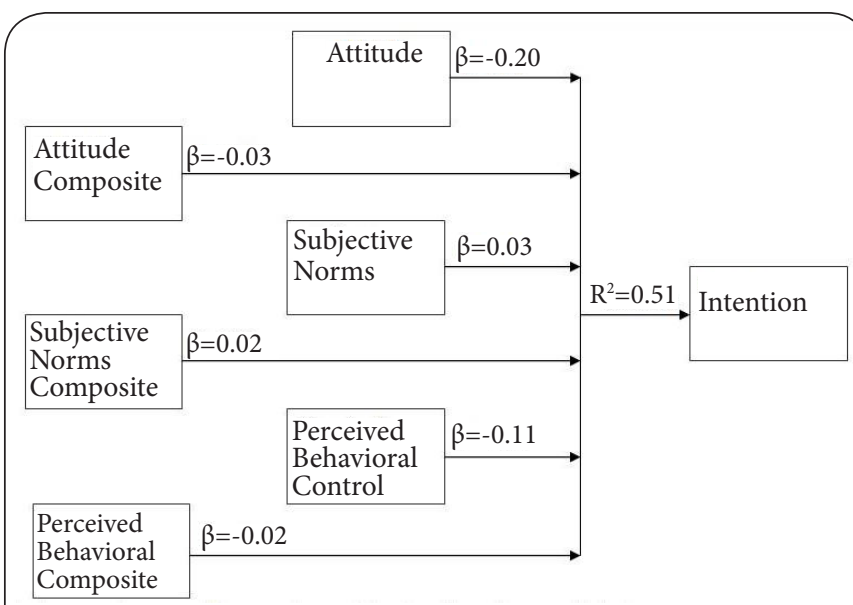

Figure 2. Theory model, regression model using all predictor variables.

\section{Discussion}

This research sought to identify leading factors in primary care providers' counseling their patients on physical activity. The theory of planned behavior seemed to provide a useful framework in which to identify determinants and evaluated intention to counsel patients on physical activity. Using the theory of planned behavior, intention to counsel was analyzed and several prediction equations were developed.

The research question resulted in two predictor variables that created a best fit model for intention. The direct measure subjective norms and the indirect measures for perceived behavioral control (composite score) proved to be the two variables that resulted in the highest correlation for intention without losing significance in the predictor variables.

Theory of planned behavior proved to be a good framework to guide research investigating the intention to counsel patients on physical activity. This finding is consistent with other research; it provides good results when evaluating intention to perform a behavior. The developed intention questionnaire enabled researchers to analyze intention by each of the constructs within the theory of planned behavior.

\section{Intention}

This study used 42 construct specific items in the final questionnaire. While this might seem long, this is similar to a study of antibiotic prescribing behaviors. Walker, Grimshaw, and Armstrong [21] created a questionnaire based on the theory of planned behavior that consisted of 66 construct specific items. These authors received $\mathrm{N}=126$ returned surveys, without providing any incentive for participation. Suggesting it is feasible to use a lengthy questionnaire and still maintain a significant sample size.

Sable and colleagues [22] found subjective norms to be of little value in their research of emergency contraception prescribing behaviors in physicians. Subjective norms did not predict intention to prescribe. The exact opposite was found in this study. In fact, this was the first predictor variable that resulted from the forward regression to develop the prediction equation. Two very different behaviors were investigated between these two studies. Personal beliefs may oppose professional organization standards to prescribe emergency contraception. The subjective norms construct is defined by what important others around you think an individual should 
do, which might put morals in conflict with what is expected by the profession. For this study, subjective norms was an influential factor in intention. Physical activity is commonly thought of as both a preventive and treatment measure for chronic disease. Because this is a widely accepted view among health professionals there was likely no discord between self or peers and the larger medical profession. It would seem, then, subjective norms is an applicable construct for this research.

Having predictor variables that result in a negative relationship with intention is less frequent. Norman, Armitage, and Quigley [23] found a negative relationship with perceived behavioral control and intention to binge drink among college students. These authors stated the possible explanation for this opposing relationship could be due to external pressures to binge drink that students saw they had little control over. This ideology could hold true in the current study. If primary care providers perceived they had little control over what screenings or discussions had to take place during a visit; physical activity not being a mandated or reimbursable issue to cover with a patient.

\section{Conclusion}

Based on these limited findings further research in physician counseling is necessary along with consideration of alternatives to physician counseling. In this particular study the direct measure Subject Norms in the theory of planned behavior made significant contributions to the variance in intention to counsel patients on physical activity. This finding is unique. This population should be further studied to identify if indeed the influence of others is the best predictor, and therefore, creating an intervention on this finding is an effective strategy for promoting physical activity for public health.

\section{Limitations}

Due to the nature of the study (a pilot effort to utilize theory in this population) a convenience sample of primary care providers was used, and lack of reliability testing resulted in an incomplete analyses of intention. There were 62 eligible primary care providers, but due to time limitations they were not all recruited; clinics with few family practitioners or internists were not included. For those primary care providers that were recruited, those that participated were asked to participate during a regular work day. Primary care providers may not have had time to complete the questionnaire due to a busy work schedule, and therefore, the answers were biased or unreliable compared to physicians who took the questionnaire on their own time. Primary care providers who participated may have been biased toward the subject matter of counseling on physical activity and influenced the results one way. Participating physicians may have also had fewer patients to see on that particular day, than did nonparticipating physicians. All of these are potential biases to the outcome.

Because of the small sample size used, a more robust analysis of intention was not performed. Other extraneous vari- ables (e.g., demographic variables) may have impacted the outcomes. Thus, these findings should be interpreted with caution. Although the research was limited by many factors, it is acknowledged this pilot study adds the current body of literature and provides insight on the direction for future research. The potential to use the Theory of Planned Behavior to identify predictors of primary care provider's behavior seems to be well-justified, and if used appropriately may lead to an increased understanding about physician counseling for physical activity.

\section{Future recommendations}

Changes in public policy may be necessary to make counseling on physical activity practical from a public health standpoint. In 2008 the American College of Sports Medicine developed a global initiative, Exercise is Medicine, in part, to provide health care providers methods and materials for prescribing and encouraging exercise. This is one step in encouraging change on a systems level. Because regular physical activity has been shown to prevent disease and promote good health [1], interventions aimed at increasing physical activity are imperative to reducing disease risk and improving health outcomes for those living with chronic disease. Continued investigation of physician's behavior would be beneficial in identifying strategies to improve primary care provider counseling and educating on physical activity.

Environmental changes in the clinic may encourage willingness in physicians to counsel patients on physical activity. Results from this study proved subjective norms to be the greatest influential factor. Quite possibly changing the culture of clinical settings to assist practicing physicians with counseling, and a shift in medical schools training of students to be more supportive of physical activity counseling interventions could influence physician's physical activity counseling behaviors; both are major shifts in ideology that can only take place with strong support from national leaders. Frank, Tong, Lobelo, Carrera, and Duperly [24], found intervening in medical students physical activity levels had the potential to increase physical activity counseling. Policy changes that provided an incentive to make physical activity counseling a priority as well as support for this type of patient education are key to behavioral changes among primary care providers. If indeed physicians are motivated to act based on the perception of what they believe others think they should do then changes in training and culture are vital to this type of public health intervention. Peer influence is a personal determinant requiring system changes to influence the general population of physicians understanding and attitudes towards physical activity counseling.

Several methodological recommendations stemmed from study findings. First, more robust recruitment measures should be put in place and ample time for recruitment should be allotted during data collection. This would better ensure a random sample of physicians participating in the research 
Behrens et al. Journal of Public Health Aspects 2014,

http://www.hoajonline.com/journals/pdf/2055-7205-1-2.pdf

doi: $10.7243 / 2055-7205-1-2$

and increase sample size. This larger sample size would allow for a comprehensive analysis of data; analyzing intention by rank (low, medium, and high) and then a physician profile can be created. A profile would provide a description of physicians by intention level. It could be determined the factors that influence low intending physicians compared to those physicians ranked as a high intending physician. One valuable demographic variable to apply as a predictor variable are primary care provider's level of physical activity. Primary care providers have been found to be more likely to recommend exercise to patients if they themselves are physically active [12]. Researches in this study heard similar statements during the elicitation interviews. This is one example of why a better understanding of what a low intending physician looks like would aid health professionals in developing and tailoring interventions to target specific primary care provider audience.

Additional recommendations based on findings from the study are strategic in nature. As noted earlier policy changes are key to successful interventions. Along with policy changes, changes to providers training and work environment (s) are vital to successful and sustained behavior change (i.e., providers consistently counseling patients on physical activity during office visits). Unfortunately, physical activity interventions based on changing policy and making environmental changes have previously been slow in development [25]. Currently, ACSM Exercise is Medicine campaign is addressing awareness of the issue and providing physicians with the tools to aid in counseling on physical activity (http://excerciseismedicine. org/physicians.htm). This is evidence that professionals in this area are becoming increasingly aware of the need for policy and environmental changes. As researches continue to develop interventions aimed at increasing physical activity on population levels, the need for quality research that guides health professionals is vital to success.

\section{Competing interests}

The authors declare that they have no competing interests.

Authors' contributions

\begin{tabular}{|l|c|c|}
\hline Authors' contributions & TKB & VJH \\
\hline Research concept and design & $\checkmark$ & $\checkmark$ \\
\hline Collection and/or assembly of data & -- & $\checkmark$ \\
\hline Data analysis and interpretation & $\checkmark$ & $\checkmark$ \\
\hline Writing the article & $\checkmark$ & $\checkmark$ \\
\hline Critical revision of the article & $\checkmark$ & $\checkmark$ \\
\hline Final approval of article & $\checkmark$ & $\checkmark$ \\
\hline Statistical analysis & -- & $\checkmark$ \\
\hline
\end{tabular}

Acknowledgement and funding

This work was supported by funding from the University of Utah Health Studies Fund.

Publication history

Editor: Paolo Roberti di Sarsina, Charity Association for Person Centred Medicine, Italy.

Received: 04-Sep-2014 Final Revised: 28-Oct-2014

Accepted: 16-Dec-2014 Published: 23-Dec-2014

\section{References}

1. Haskell WL, Lee IM, Pate RR, Powell KE, Blair SN, Franklin BA, Macera CA, Heath GW, Thompson PD and Bauman A. Physical activity and public health: updated recommendation for adults from the American College of Sports Medicine and the American Heart Association. Med Sci Sports Exerc. 2007; 39:1423-34. | Article | PubMed

2. U.S. Department of Health and Human Services. Physical Activity and Health: A Report of the Surgeon General. Washington D.C: US Department of Health and Human Services. 1996. I Website

3. Hoyert D and Xu J. Deaths: Preliminary data for 2011. National Vital Statistics Reports. 2012; 61. | Pdf

4. US Department of Health and Human Services. Approximately $\mathbf{\$ 4 0}$ million in affordable care act funds for statewide chronic disease prevention programs. US Department of Health and Human Services. 2011. | Website

5. US Department of Health and Human Services. Physical activity guidelines for Americans. Office of Disease Prevention and Health Promotion. 2008. | Website

6. US Department of Health and Human Services. Healthy People 2020. Office of Disease Prevention and Health Promotion. 2010.

7. Meriwether RA, McMahon PM, Islam N and Steinmann WC. Physical activity assessment: validation of a clinical assessment tool. Am J Prev Med. 2006; 31:484-91. | Article | PubMed

8. Albright CL, Cohen S, Gibbons L, Miller S, Marcus B, Sallis J, Imai K, Jernick $J$ and Simons-Morton DG. Incorporating physical activity advice into primary care: physician-delivered advice within the activity counseling trial. Am J Prev Med. 2000; 18:225-34. | Article | PubMed

9. Manson JE, Skerrett PJ, Greenland P and Vanltallie TB. The escalating pandemics of obesity and sedentary lifestyle. A call to action for clinicians. Arch Intern Med. 2004; 164:249-58. | Article | PubMed

10. Woolf SH, Krist AH, Johnson RE, Wilson DB, Rothemich SF, Norman GJ and Devers KJ. A practice-sponsored Web site to help patients pursue healthy behaviors: an ACORN study. Ann Fam Med. 2006; 4:148-52. | Article | PubMed Abstract | PubMed Full Text

11. Vanwormer J, Pronk $\mathrm{N}$ and Kroeninger $\mathrm{G}$. Clinical counseling for physical activity: Translation of a systematic review into care recommendations. Diabetes Spectrum. 2009; 22:44-55. | Article

12. Gemson DH and Elinson J. Prevention in primary care: variability in physician practice patterns in New York City. Am J Prev Med. 1986; 2:226-34. | PubMed

13. Ajzen I, Albarracin D and Hornik R. Prediction and change of health behavior: Applying the reasoned action apporach. 2007.

14. Fishbein $M$ and Ajzen I. Belief, attitude, intention, and behavior: An introduction to theory and research. 1975.

15. Elder JP, Ayala GX and Harris S. Theories and intervention approaches to health-behavior change in primary care. Am J Prev Med. 1999; 17:27584. | Article | PubMed

16. Francis J, Eccles M, Johnston M, Walker A, Grimshaw J and Foy R et al. Constructing questionnaires based on the theory of planned behaviour. A manual for health researchers. University of Newcastle. 2004. I Pdf

17. Godin G. Theories of reasoned action and planned behavior: usefulness for exercise promotion. Med Sci Sports Exerc. 1994; 26:1391-4. | Article I PubMed

18. Godin $\mathrm{G}$ and Kok $\mathrm{G}$. The theory of planned behavior: a review of its applications to health-related behaviors. Am J Health Promot. 1996; 11:87-98. | PubMed

19. US Department of Health and Human Services. Theory at a glance: A guide for health promotion practice. National Cancer Institute. 2005.

20. Godin G, Belanger-Gravel A, Eccles M and Grimshaw J. Healthcare professionals' intentions and behaviours: a systematic review of studies based on social cognitive theories. Implement Sci. 2008; 3:36. | Article | PubMed Abstract | PubMed Full Text

21. Walker AE, Grimshaw JM and Armstrong EM. Salient beliefs and intentions to prescribe antibiotics for patients with a sore throat. $\mathrm{Br} J$ Health Psychol. 2001; 6:347-360. | Article | PubMed 
Behrens et al. Journal of Public Health Aspects 2014,

http://www.hoajonline.com/journals/pdf/2055-7205-1-2.pdf

22. Sable MR, Schwartz LR, Kelly PJ, Lisbon E and Hall MA. Using the theory of reasoned action to explain physician intention to prescribe emergency contraception. Perspect Sex Reprod Health. 2006; 38:20-7. I Article I PubMed

23. Norman P, Armitage CJ and Quigley C. The theory of planned behavior and binge drinking: assessing the impact of binge drinker prototypes. Addict Behav. 2007; 32:1753-68. | Article I PubMed

24. Frank E, Tong E, Lobelo F, Carrera J and Duperly J. Physical activity levels and counseling practices of U.S. medical students. Med Sci Sports Exerc. 2008; 40:413-21. I Article I PubMed

25. Sallis JF, Bauman A and Pratt M. Environmental and policy interventions to promote physical activity. Am J Prev Med. 1998; 15:379-97. | Article I PubMed

\section{Citation:}

Behrens TK and Harbour VJ. Physician intention to counsel on physical activity: results from a pilot theory of planned behavior questionniare. J Public Health Aspects. 2014; 1:2.

http://dx.doi.org/10.7243/2055-7205-1-2 